\title{
Золтан Надь
}

\section{«БЕРЕГИНЯ», ПРОСЛАВИВШАЯ ВАСЮГАНСКИХ ХАНТЫ}

\begin{abstract}
В статье в формате культурной антропологии рассматривается жизнедеятельность Надежды Брониславовны Вяловой, считающей себя представительницей народа ханты. Настоящая статья имеет иелью рассмотреть, как творчество Вяловой вписывается в ту характерную для Сибири ситуацию, когда этнические группы, утратившие свой традиционный образ жизни и искусство, на этапе пробуждения этнического самосознания обновляют и вновь усваивают традичионные культурные формы, а также создают новые, т.е. творят созданные традиции.

Ключевые слова: ханты, Западная Сибирь, изобретение традищий, унаследованный язык, коренный антрополог, фольклоризация.
\end{abstract}

Надежда Брониславовна Вялова - уникальный человек. Вероятно, мало кто может похвастаться тем, что является самой выдающейся личностью своего района ${ }^{1}$. Между тем глава администрации Каргасокского района Андрей Петрович Ащеулов представил Вялову ведущим деятелям культурной политики области следующим образом: «самый известный человек не только нашего Каргасокского района, но и всей Томской области» [1]. Подобное утверждение может показаться несколько неожиданным, особенно если учесть, что Вялова относит себя к народу ханты, т.е. является представительницей довольно-таки низкопрестижной группы коренного меньшинства в районе, где $90 \%$ населения - русские, а численность ханты не достигает и $1 \%$ [2]. Так кто же она, эта хантыйская женщина?

\section{Жизненный путь}

Надежда Брониславовна Вялова родилась в 1952 г. в дер. Забегаловка Томской области, расположенной недалеко от р. Васюган. Определяющую роль в жизни Вяловой сыграло происхождение по материнской линии, ставшее основой ее этнической идентичности: ее дед по матери был ханты из ро$\partial a^{2}$ Мурасовых, пришедших, по словам Вяловой, на Васюган с р. Сыни ${ }^{3}$. Как утверждает Вялова, семья деда поначалу жила в достатке, члены семьи занимались рыбалкой и охотой, однако после того, как с приходом все большего числа русских поселенцев площадь охотничьих и рыболовных угодий резко сократилась, семья переселилась на Тым. По ее сведениям, там умерли от

\footnotetext{
${ }^{1}$ Каргасокский район Томской области, Россия.

${ }^{2}$ Словоупотребление Вяловой. Здесь и далее в тексте цитированные нами слова, выражения и фразы Вяловой выделены курсивом.

${ }^{3}$ Мурасовы действительно не относятся к коренным родам васюганских ханты [3], вместе с тем согласно записям метрических книг, на рубеже XIX-XX вв. на Васюгане проживало уже несколько представителей этого рода, главным образом в пос. Усть-Чижапка. По свидетельству составленного Вяловой генеалогического древа семьи, ее прапрадед уже родился здесь в 1867 г. Вероятнее всего, семья принадлежала к александровским ханты: на территории Александровского района существовало поселение с названием Мурасово.
} 
черной оспы первая жена и два сына деда, поэтому с оставшимися тремя сыновьями дед вернулся на Васюган. Здесь он встретился в лесу с будущей второй женой и ее братьями, к тому времени уже осиротевшими. Два старших брата договорились с дедом Вяловой, что сестру выдадут за него замуж и будут вместе воспитывать трех его сыновей, а также своих младших сестру (бабушку Вяловой) и брата.

Семья бабушки по материнской линии прошла долгий путь до того, как попасть на Васюган. Родом из Омской области, наполовину русская, наполовину чувашская семья сначала попытала счастья в добыче золота на Амуре, но безуспешно, поэтому отправилась в Томск, откуда, в надежде на большую удачу в охотничьем и рыболовном промысле, приехала на Васюган. Здесь умерли прадед и прабабушка Вяловой, и здесь братья выдали замуж ее бабушку.

В 1942 г. дед Вяловой был арестован за то, что «незаконно» ловил рыбу для своей семьи; после ареста он больше не вернулся домой. Мать Вяловой была еще маленькой, когда семья осталась без кормильца, и по причине тяжелых условий жизни Вялова - как и ее младшая сестра и двоюродные братья и сестры - была внебрачным ребенком. Ее родной отец был русский, родом из деревни, расположенной недалеко от райцентра, но семья не поддерживала с ним никаких отношений. Позже мать вышла замуж за белорусского поляка, и Вялова взяла его фамилию и отчество. Родители отчима были партизанами на оккупированной немецкими войсками территории; во время одного из обысков маленькую Надежду «запинали» под кровать, в результате чего она стала инвалидом. Травму головы, вследствие которой врачам пришлось вставить ей в череп металлическую пластину, она получила, когда после расстрела родителей отчима по дороге в сиротский приют она сбежала, выпрыгнув из поезда.

Вяловой исполнилось десять лет, когда она начала учиться в школеинтернате в с. Усть-Чижапка. В селе в то время было два интерната: один для детей спецпоселенцев, другой - для детей коренных «остяков» ${ }^{1}$ и детей из неполных семей. Из двух школ «остяцкий» интернат пользовался меньшим почетом, ученики из другой школы часто дразнили живущих здесь детей, Вяловых же, которые были незаконными, обижали особенно часто. К этому времени семья переехала из Забегаловки в Уралку, где ей также приходилось терпеть много оскорблений из-за своего остяцкого происхождения, так как в деревне, кроме них, жили только семьи спецпереселенцев.

Поздно начав обучение в школе, Вялова окончила обязательные в те годы десять классов в двадцать лет. Она хотела поступить в Томский педагогический институт на физико-математическое отделение, но как-то на улице ей стало плохо и, проведя полтора месяца в больнице, она пропустила срок поступления в вуз. Сначала Вялова устроилась на работу в дом культуры в деревне родителей, затем стала работать в своей бывшей школе учителем математики. До ухода на пенсию она работала учителем в разных школах, где преподавала главным образом естественнонаучные и творческие предметы, была также культработником в домах культуры, киномехаником и библиотекарем - для этого приобрела специальную квалификацию.

\footnotetext{
${ }^{1}$ В местном словоупотреблении «остяками» называли не только ханты, но и селькупов.
} 
С Виктором Вяловым, имеющим русские и латышские корни, они поженились в 1970 г. в Наунаке. В сталинские времена семья Виктора была дважды объявлена кулацкой и сослана в Сибирь. Супруги вырастили пятерых детей, и к моменту написания данной статьи у них десять внуков. Живут в 6 км от райцентра Каргасок, в дер. Бондарка, где к настоящему времени уже нет никаких общественных услуг.

Вялова рано ушла на пенсию, в 46 лет: для жителей северных территорий установлен льготный пенсионный возраст, однако такой ранний выход на пенсию обусловлен также тем обстоятельством, что школа, в которой работала Вялова, была закрыта. Чтобы заполнить свой досуг, она занялась ремесленничеством. Обращалась к разным видам ремесел: занималась резьбой по дереву, изготавливала посуду из бересты, плела корзины из лозы, плела бисером, вязала, шила, мастерила куклы. Это совпало с тем временем, когда в 2000 г. активизировались движения северных народов [4. С. 5], что пробудило ее интерес к культуре васюганских ханты, и из доступных ей книг она стала глубже изучать эту тему. Вялова все активнее принимала участие в жизни хантыйских этнических культурных групп: в районном центре была создана национальная община, а в 2004 г. был основан клуб «Ай пяях» 1 , главная цель которого состояла в изучении, сохранении и пропаганде хантыйских традиций. Этот клуб существовал почти десять лет.

В 2002 г. Вялова нашла тот жанр, в котором смогла в полной мере реализовать себя: искусство вырезания картин из бумаги. Вялова вырезает свои картины с помощью маленьких ножниц из простой белой бумаги, без какоголибо предварительного плана или эскиза. В последнее время она, как правило, наклеивает вырезки на цветной фон и ламинирует их. Ее картины уникальны, неповторимы даже для нее самой, поэтому очень скоро она оставила попытки продублировать их: Однажды мне хотелось повторить картину, я поставила ее перед собою, попыталась вырезать то же самое, но получилась пародия. Благодаря густым прорезям, узоры Вяловой отличаются тонкостью, воздушной легкостью и ритмичностью. Картины обрамлены орнаментами со стилизованными изображениями животных и растений, напоминающими хантыйские мотивы. Фигуры изображены то в «негативе», то в «позитиве». Она пробовала также работать лезвием, но узоры получались слишком угловатые, не удавалось как следует отработать линии силуэтов. Вырезанки Вяловой приобретали все большую популярность, однако всеобщее признание ее творчество получило в 2010 г.: благодаря выставке в Каргасоке, ее высокой посещаемости, а также ряду статей, появившихся в прессе, ее имя стало известным практически по всему району.

Свою просветительскую деятельность Вялова начала еще до 2010 г. Она посещала детские сады и школы с небольшими, соответствующими возрасту детей программами, в которых рассказывала о жизни ханты, о природе, а также короткие, со временем больше в стихотворной форме, истории. В сказки, которые она называет хантыйскими, изначально включались только отдельные хантыйские слова, но сейчас она рассказывает их на двух языках хантыйском и русском. Свои рассказы Вялова иллюстрирует собственными вырезками или сопровождает их небольшими спектаклями, используя при

\footnotetext{
${ }^{1}$ По словам Вяловой, «ай пяях» в переводе на русский язык означает 'все до кучи' ([21. С. 35]: ӓй пяях - в одну кучу).
} 
этом деревянные и тряпичные куклы. Просветительские программы Вяловой иногда сопровождаются показом фотографий через проектор и демонстрацией бытовых предметов собственного изготовления. Свои выступления она всегда начинает игрой на варгане. Основной темой ее выступлений, помимо местной природы, является жизнь васюганских ханты: созданные ею изделия и сказки она преподносит как хантыйское наследие, каждый раз надевает хантыйский костюм, чтобы таким способом также подчеркнуть свою этническую принадлежность.

Вялова поставила перед собой твердую цель: сделать хантыйскую культуру общим достоянием и добиться ее признания. Средством достижения этой цели она выбрала народное творчество [5. С. 91], так как, по ее словам, дети познают окружающий мир главным образом через предметы [6. С. 1], она же в своих выступлениях обращается прежде всего к детям. Именно по этой причине Вялова считает особенно важным, чтобы ее выступления были увлекательными, ведь дети только так хотят и любят учиться. «Хочется, чтобы будущее поколение не забывало нашу историю, традиции, прошлую жизнь. Не отказываясь от нового, надо помнить и чтить старое» [7. С. 135]. Поэтому, чтобы привлечь внимание детей, свои занятия она обыкновенно начинает словами: Ребята, сейчас я вам расскажу то, чего нет в интернете [8].

В творчестве Вяловой так тесно переплетаются народное искусство и возрождение хантыйской культуры, что даже свое обращение к народным ремеслам она связывает с началом развития движений коренных народов [9. С. 46]. Себя она считает хранительницей, спасительницей:

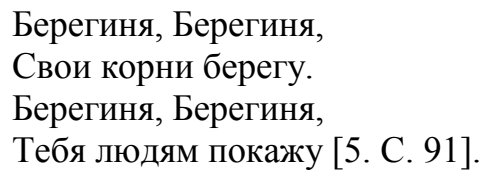

Сегодня Вялова стала «брендом» [9], маркой Каргасокского района. Выпускаются серии открыток и магниты для холодильников с ее вырезанками, в местных изданиях небольшим тиражом публикуются иллюстрированные стихотворения Вяловой, принты ее картин печатаются на футболках и рубашках, есть даже наклейки на заднее стекло автомобиля или на фасад дома. Был издан альбом-каталог ее работ «Сибирские вырезанки» [11]; также она создавала иллюстрации к сборнику сказок [12]. С выставками и выступлениями Вялова объездила весь район и область, выступала в Москве, Абакане, Новосибирске, Сургуте, Ханты-Мансийске и, конечно же, в Томске, ее приглашали также в г. Харбин в Китае. Она вела курсы в Томском педагогическом университете, является постоянной участницей местных этнических фестивалей, творческих лагерей, ярмарок. За свою деятельность Вялова получила множество почетных званий и наград ${ }^{1}$. В 2013 г. ее творчество было внесено в каталог нематериального культурного наследия Томской области [13], а в 2014 г. по решению областного комитета ей была присуждена победа в конкурсе «Женщина года» в номинации «Творческая личность» за «вклад в дело возрождения и популяризации культуры и традиций коренных народов

\footnotetext{
${ }^{1}$ Перечень званий и наград Вяловой приводится в отдельной главе в альбоме «Сибирские вырезанки».
} 
Севера, а также воспитания подрастающего поколения в духе любви к истории родного края» [14]. В этом же году решением районного комитета ей было присуждено почетное звание «за подвижничество в культуре».

\section{Творческая деятельность}

Сегодня Надежда Вялова - самый известный человек среди васюганских ханты. По словам вышеупомянутого главы райадминистрации, «картины Надежды Вяловой сделали васюганских хантов известными, может, не на весь мир, но во всяком случае во многих его уголках» [1]. Ее называют послом хантыйской культуры, «благодаря ей о васюганских хантах знают многие». Оценить по достоинству роль Вяловой можно только с учетом того факта, что в течение последних десятилетий васюганские ханты практически полностью отсутствовали в публичных дискурсах как отдельных поселений, так и района, а тем более области. Эта «невидимость» обусловлена демографическими, социальными, экономическими и политическими факторами, однако главной причиной все же следует считать отсутствие экзотичности: культура васюганских ханты рано была русифицирована, практически не содержала самобытных элементов, претендующих на всеобий интерес, не имела такого культурного символа, художника или этнического предпринимателя, которые могли бы привлечь внимание широкой аудитории. Вместо того чтобы стать признанной обществом этнической группой, обладающей самобытной культурой, васюганские ханты, как правило, люмпенизировались, окружающие относились к ним как к маргинальной группе, поэтому они не имели места и в коллективной памяти области [15]. В этом контексте стала известным художником и знаменитостью Вялова, подчеркивающая свою принадлежность к народу ханты и считающая себя представительницей и хранительницей его культуры, причем такая оценка ее личности и творчества еще решительнее высказывается на местных общественных форумах. Благодаря ее деятельности общественное мнение района обнаружило экзотичность этой этнической группы, привлекшей общее внимание и вызвавшей интерес к культуре своего народа.

В свете вышесказанного нет ничего удивительного в том, что творчество Вяловой воспринимается окружающими как аутентичное творчество васюганских ханты. Подобным образом расценивает свое творчество и сама Вялова, однако ее высказывания по этому поводу гораздо более осторожны. Она обыкновенно говорит, что вдохновение, мотивы и предания она черпает из своего детства: с детства я хорошо помню. Вообще всю свою деятельность она объясняет тем, что с детства я была свидетелем того, как вокруг меня люди все что-то «мастерили» [16. С. 126]. Такая сдержанность в высказываниях весьма понятна, ведь родители Вяловой жили не в хантыйской среде, не по хантыйским обычаям, единственный в семье хантыйский предок дед по матери - умер за десять лет до ее рождения, следовательно, у нее не было возможности узнать изнутри культуру васюганских ханты, которая в то время претерпевала существенные изменения. Помимо воспоминаний детства, источником творчества для нее служат также литературные источники: после выхода на пенсию она стала читать книги про васюганских ханты, орнаментальные мотивы и узоры находила в альбоме восточных хантыйских орнаментов Лукиной [17], много раз перечитывала дневник Сирелиуса, в ко- 
тором, по ее словам, она обнаружила портрет своего предка [18. С. 39], а для сказок, которые вспльвают из памяти, приходят из детства, важным источником является фольклорный сборник [19].

Здесь хотелось бы несколько подробнее остановиться на некоторых вопросах, возникающих в связи с творчеством Вяловой. До настоящего времени она смастерила около 70 кукол, часть из них раздарила. Эти куклы-обереги довольно большие, одеты в простую одежду, внутрь которых она кладет свернутый в скалку кусок ткани, чтобы куклы могли стоять. Какие были куклы-обереги у васюганских ханты, на сегодня ввиду отсутствия источников с точностью установить невозможно, однако можно сказать, что куклы у ханты, как правило, меньшие по размеру, внутри пусты и одеты в нарядную одежду. Игра на варгане также не вполне соответствует васюганским традициям, поскольку варган, используемый Вяловой, - это алтайский музыкальный инструмент, изготовленный из металла, в то время как у васюганских ханты варган изготавливали в основном из кости или дерева, его форма и принцип действия отличались от алтайского: он приводился в движение не пальцем, а посредством дергания за нитку [20. С. 126]. Вышитые орнаментами хантыйские сумки Вяловой больше походят на подарочные изделия сувенирных магазинов, а используемое ею хантыйское название означает сумку для иголок [21. С. 93]. Также она шьет сумки и одеяла в лоскутной технике: Американцы говорят, пэчворк. Но на самом деле ханты всегда занимались этим, традиционно.

Вид творчества, в котором Вялова получила широкую известность, техника художественного вырезания из бумаги. Эта техника не имеет предпосылок в хантыйской культуре, если не считать того, что одним из пяти возможных способов декорирования бересты Сирелиус называет вырезной [22. С. 193], сама Вялова также не утверждает обратного. По ее словам, вырезание из бумаги напоминает ей о детстве: мать вырезала из газетной бумаги занавески, украшенные орнаментом с изображениями животных и растений, полки украшали бумажным кружевом, Вялова же часто вырезала салфетки, подстаканники, снежинки на окна. С техникой вырезания из бумаги она познакомилась гораздо раньше, чем с рисованием: по ее признанию, карандаш она впервые увидела в школе. В опубликованных интервью и беседах Вялова отмечает, что ее техника уникальна, не имеет аналогов во всем мире ${ }^{1}$ [23], а прообразами для ее картин служат только далекие воспоминания детства. Если прежде она говорила о том, что хотела перенести свою технику на бересту, но эта попытка оказалась безуспешной [9. С. 47], то к настоящему времени она все чаще интерпретирует это так, будто первоначально вырезание было хантыйской техникой декоративной обработки бересты, с которой она и

\footnotetext{
${ }^{1}$ Вырезание из бумаги - широко распространенный вид искусства в Китае, который в 2009 г. был внесен ЮНЕСКО в Список всемирного культурного наследия (ср.: McCormick, Charlie T., Kennedy White, Kim. Santa Barbara. (eds.) Folklore. An encyklopedia of beliefs, customs, tales, music and art. 1. 2011: 285; Terebess Ázsia Lexikon = http://terebess.hu/keletkultinfo/lexikon/papirkivagas.html; Tóth Andrea Judit: A papírkivágás müvészete. = Konfuciusz Krónika 2010/2. = http://www.konfuciuszintezet.hu/ index.php?menu=muveltseg\&almenu=8\&cikkszam=53). Кроме того, вырезание из бумаги используется и в других точках мира, в Европе с XVIII в. особенно популярной его формой стала техника вырезания силуэтов, среди которых наиболее известными являются бумажные силуэты Ганса Христиана Андерсена: Hans Christian Andersen's Paper Cuts in The Royal Library-http://wayback01.kb.dk/wayback/20101108104614/http:/www2.kb.dk/elib/mss/hcaklip/index-en.htm
} 
начала работать, но позже из экологических соображений заменила бересту на бумагу, чтобы не портить деревья [23].

Общественность охотно признала эту технику как уникальную форму хантыйского искусства: «яркий пример самобытного орнаментального искусства, распространенного среди хантов» [24]. Более того, указание на близость творчества Вяловой к традициям хантыйского декоративно-прикладного искусства уже появилось и в специальной литературе. Согласно утверждению Рындиной [25], вырезанки Вяловой несомненно можно сроднить с хантыйской техникой вырезания из бересты. В пользу этой связи Рындина приводит следующие аргументы: и в той и в другой технике мастер работает без шаблона; узоры вырисовываются с помощью изогнутых линий; несмотря на существование общих композиционных принципов, каждый мотив неповторим; большую роль играет импровизация. По ее мнению, существенная близость обнаруживается на уровне композиции: все три канона художественной обработки бересты у васюганских ханты - орнаменты в форме зигзага с асимметричными ответвлениями, ряды из ромбов, стилизованные изображения животных, прежде всего медведя, присутствуют и в творчестве Вяловой. Кроме того, сходство усматривается также в технике выполнения сюжетных изображений: сюжет, помещенный в округлую рамку с орнаментом, вырисовывается за счет сложных, часто симметрично расположенных фигур. Причину этой близости Рындина усматривает в традиционном мировоззрении, присущем Вяловой точно так же, как и васюганским ханты. Поскольку же Вялова выросла не в хантыйской среде, то Рындина выдвигает предположение о подсознательном унаследовании традиций. Вместе с тем, на наш взгляд, не следует упускать из виду, что частое изучение орнаментальных мотивов васюганских ханты, которое Вялова считает краеугольным камнем в развитии своего творчества, также может быть причиной этого кажущегося несомненным сходства. То есть техника, которая первоначально не считалась традиционной для васюганских ханты, сегодня все более интерпретируется как самой Вяловой, так и общественностью и даже специальной литературой как аутентичное хантыйское искусство, что имеет принципиальное влияние на восприятие ее творчества окружающими.

Подобный процесс можно проследить и в употреблении Вяловой хантыйского языка во время выступлений. Как отмечалось выше, в первое время она вставляла лишь отдельные хантыйские слова в русскоязычные тексты, но сейчас уже ее выступления проводятся на двух языках. Употребление хантыйского языка уже само по себе представляется неожиданным, так как в настоящее время на территории Васюганья живут лишь несколько стариков (или я не осведомлен об их смерти), которые свободно, на уровне повседневного общения, говорят на хантыйском языке. Среди представителей среднего поколения находятся такие, кто пассивно владеют языком, многое понимают и даже используют некоторые выражения. Тем не менее можно сказать, что процесс смены, утраты языка почти полностью завершился в бассейне p. Васюган. Вялова не принадлежит к числу тех немногих, кто понимает хантыйский язык, ни тем более к тем, кто им владеет. У нее, в сущности, и возможности не было выучить хантыйский язык. Вялова и не утверждает обратного: можно сказать, что я совсем не говорю по-хантыйски. После смерти деда связь с семьей Мурасовых прервалась и услышать хантыйскую речь бы- 
ло не от кого. В Наунаке жила одна старушка, с ней, когда бывали в гостях, мать иногда разговаривала по-хантыйски, но Надежду в таких случаях всегда отправляли из кухни. Основным источником хантыйской речи Вяловой является изданный в 1996 г. хантыйско-русский словарь, составленный на склоне лет Маркелом Кондратьевичем Могутаевым, жителем Айполово. Из этого весьма своеобразного словаря, в котором слова переводятся только с хантыйского языка на русский, Вялова кропотливым трудом выбирает нужные ей слова и, соединяя их в ряд, создает так называемый хантыйский текст. По сути дела, для нее важен не столько смысл этого текста, ведь то же самое она говорит и по-русски, сколько мелодичность языка. По ее словам, она с детства помнит звучание хантыйского языка, которое и пытается воссоздать. Одна пожилая родственница, когда услышала ее рассказы, с гордостью подтвердила: «Надежда, ты совсем остячкой сделалась». Для нее главное, чтобы дети - будь они русские или ханты, никогда раньше не слышавшие хантыйский язык, «смогли почувствовать красоту и удивительную мелодичность этого языка» [26]. Она считает успехом, если в начале выступления ей удается преодолеть детский смех ${ }^{1}$, и для нее большая радость, что дети внимательно слушают ее рассказы ${ }^{2}$, им нравится хантыйский язык.

\section{Аутентичность}

На основе всего вышеизложенного можно с уверенностью утверждать, что художественный мир и язык, представленные в творчестве Надежды Брониславовны Вяловой, имеют лишь весьма отдаленное отношение к тому, что мы знаем о культуре и языке васюганских ханты из ретроспективных этнографических исследований и источников того времени. Тем не менее исследовать данный феномен представляется куда более интересным и важным, чем предъявлять к нему требование аутентичности.

Нужно сказать, что рассматриваемое нами явление отнюдь не является единичным, напротив, в тех районах - а особенно это характерно для Сибири [27], где возникает необходимость презентации той или иной этнической культуры, но практически нет такого вида искусства, деятельности или нарративного жанра, которые можно было бы предъявить в качестве традиционных, этнические предприниматели весьма часто прибегают к разного рода обновлениям, реконструкциям и заимствованиям. Эти «изобретенные» культурные товары этнические предприниматели затем утверждают как аутентичные, прежде всего посредством своего авторитета, поскольку аудитория считает их подлинными представителями данной культуры. Следовательно, то, что они демонстрируют, и становится аутентичной этнической культурой. Однако не меньшую роль в утверждении аутентичности играет и сама аудитория: то, что вызывает интерес, что отвечает представлениям об экзотичности и соответствует сложившимся о данной этнической культуре стереотипам, общественность охотно принимает как аутентичное, признает его

${ }^{1}$ «И самое главное, если я начинаю говорить, сначала все смеются. Я говорю: ребята, мы удивительные люди, как эти наши..., значит, когда американцы..., да, слушаем американцев и англичан по телевизору, тогда не удивляемся, не смеемся, а вот смеемся над тем, над языком, на котором говорили наши предки. Наши, вот эти люди, в смысле, старые люди. А мы над этим смеемся».

2 «А когда я говорю, рассказываю это детям, настолько они, знаете, говорят: «ну, пожалуйста», многие вот с этими своими телефонами: „пожалуйста, скажите еще что-нибудь, еще что-нибудь“». 
подлинным, самобытным, а вместе с тем и традиционным, архаичным. Разумеется, такой положительный отклик со стороны общественности оказывает благоприятное воздействие и на данную этническую группу: укрепляет ее этническое самосознание и способствует накоплению коллективного капитала, необходимого в борьбе за экономические и политические ресурсы.

Подобное явление наблюдается, к примеру, у селькупов, проживающих на территории Томской области: эта тенденция отражается, в частности, в жанровых сценках из народного быта, в обработках селькупских сказаний, в репертуаре хореографического ансамбля, в шаманских сеансах, входящих в программу фестивалей и государственных праздников, а также в регулярно устраиваемых селькупских национальных праздниках и фестивалях [28-32]. Употребление Вяловой хантыйского языка, которое, с некоторыми оговорками, можно охарактеризовать как пример употребления «унаследованного» языка (heritage language) [33], также имеет свои аналогии в Томской области: так, например, Ирина Коробейникова не только свободно говорит и пишет на селькупском языке, но и занимается обратным переводом селькупских текстов, известных только на русском языке [34]. Подобное отношение к использованию родного языка наблюдается у шорцев, проживающих на территории Кемеровской области. При изучении языковых установок шорцев выяснилось, что среди городской молодежи знание «своего» языка считается желательным, вместе с тем владение русским языком является обязательным, а иностранным языкам отдается предпочтение перед шорским языком. Тем не менее шорскому языку они придают глубокое символическое значение, считают его своим родным языком и хотели бы, чтобы их дети говорили на нем. Несмотря на то, что шорский язык перестал употребляться в качестве повседневного средства общения, в рамках городских фестивалей он остается важной частью праздничной, сценической культуры [35].

Как видим, в Сибири сейчас, в постсоветское время, наблюдается тенденция массового производства, изобретения традиций, значимость которых заключается не в их соотнесенности с реальным или воображаемым прошлым (вопрос о подлинности или фиктивности в данном случае является несущественным), а в том, какое влияние эти традиции оказывают в настоящем $^{1}[36,37]$. Таким образом, в этой связи правильнее ставить вопрос не об аутентичности изобретенных традиций, а об их эффективности. А как мы видим из приведенных выше примеров, деятельность Вяловой весьма эффективна, по крайней мере с точки зрения мажоритарного общества, ведь ей удалось включить васюганских ханты в публичные дискурсы, обратить на них внимание общественности. Разумеется, немаловажную роль в успехе Вяловой играет и то, каким способом она преподносит аудитории свои темы. С одной стороны, в отличие от доминирующего нарратива памяти, в котором ханты исключаются из истории региона [15], Вялова стремится сделать хантыйское наследие общим достоянием человечества, общей культурной ценностью2. Иными словами, она попросту оставляет без внимания тот факт, что

\footnotetext{
${ }^{1}$ О способе изобретения традиций в Китае см.: Sárközi, Ildikó Gyöngyvér. From the Mists of Martyrdom: Sibe Ancestors and Heroes on the Altar of Chinese Nation-Building /'Halle Studies in the Anthropology of Eurasia/ Halle : Lit Verlag, 2018.

${ }_{2}$ Вялова всегда подчеркивает, что главной своей целью она считает сохранение и возрождение исчезающей культуры ханты и селькупов, развитие народного творчества.
} 
историческая память мажоритарного населения не тождественна памяти ханты, и в своих выступлениях смешивает их. «Дети хотят знать, как жили их предки», - говорит Вялова, и поэтому свои сказки она рассказывает на двух языках, чтобы «дети слышали звучание родной речи» [7. С. 131]. С другой стороны, в ее выступлениях присутствует также своего рода экологическая сознательность: экологическое сознание, близость к природе и гармоничное сосуществование с ней, чувство имманентной принадлежности к тайге являются теми маркерами, которые в мажоритарном обществе считаются особенно важными в отношении коренных этнических менышинств [38]. Вялова нередко говорит о том, что она волнуется за природу, ее тревожит загрязнение окружающей среды, вырубка лесов, безмерное уничтожение рыбы и диких животных. По ее словам, именно поэтому очень важно пропагандировать хантыйскую культуру, ведь давно люди - читай ханты - жили в гармонии с природой, старались наносить ей как можно меньше вреда и брали от нее ровно столько, сколько нужно было для пропитания [7. С. 130]. Если обратить внимание на названия ее выступлений, то можно заметить, что в них также присутствует указанная выше двойственность тематики: хантыйская культура, народное творчество, представленные как общее наследие, с одной стороны, и лес, тайга - с другой. Вот несколько примеров: «Быт и традиции народов Севера», «Народное творчество и современность», «Символы мира в изделиях народного творчества», «Речные люди», «Таежные люди».

За последние десятилетия никому не удавалось с такой силой показать и вовлечь в публичные дискурсы культуру васюганских ханты, как Вяловой. Более того, как мы видели, ее творчество стало не только этническим, но и локальным «товарным знаком»: ее вырезанки стали «брендом как Каргасокского района, так и всего региона» [1]. А это, в свою очередь, может послужить солидным политическим капиталом в случае, если найдется такой этнический предприниматель или (этно)политический деятель, который поставит целью представлять или использовать интересы этой этнической группы на политической арене. Как видно, реализация этой возможности в этнополитических целях все еще заставляет себя ждать, в настоящее время гораздо более существенным является ее внедрение в региональный дискурс, ведь Вялова, «женщина 2014 года», своим самобытным творчеством представляет весь район. Это особенно важно как для местных политических деятелей - так как Вялова со своими выставками не только принимает активное участие в крупнейших форумах области, но при случае может передать ценный подарок губернатору области [39], так и для самой Вяловой, которая на торжественном открытии национального клуба «Диалог» сказала следующее: «Давно мечтала, чтобы у нас был такой клуб национальных культур. И, возможно, мы не будем сосредотачиваться на одной народности, как это делаю я. Все мы - носители русского языка. И почему бы нам, всем вместе, в рамках нового клуба не сделать русский костюм, не сценический, а настоящий, национальный...» [40].

Не менее интересным для изучения представляется вопрос о том, оказывает ли творчество Вяловой какое-либо влияние на формирование этнической идентичности самих васюганских ханты, и вообще, как они относятся к нему, признают ли его своим национальным искусством? В этом направлении исследования пока не проводились, тем не менее, по моим наблюдениям, ханты 
Каргасокского района ценят творчество Вяловой, видят в ее просветительской деятельности шанс на улучшение своего положения.

\section{Наивный художник и ученый}

Как об этом упоминалось выше, Надежда Брониславовна Вялова в своих выступлениях рассказывает сказки, которые сочиняет сама. Эти сказки она часто визуализирует, т.е. иллюстрирует, разыгрывает действие с помощью кукол и вырезанок. Свои стихи Вялова, как правило, пишет на хантыйском и на русском языках в форме рифмованного, ритмизированного текста. Ее стихосложение скорее можно назвать наивно-милым, нежели профессиональным:

\section{Ёнк-Юнк и Яряк}

(Водяной дух и ёрш)

«Ёнк-Юнк хранит реку!»-

Говорили в старину.

Ёнк - вода, юнк - свят дух.

Был в правду такой слух.

В Вас-юхане ёрш Яряк

Жил совсем не просто так.

Мелких рыбок поедал,

А большуших разгонял.

Эту саму кутерьму

Ёнк-юнк видел наяву.

Решил Яряка наказать,

В омуточек зло загнать.

Нет там света, нет еды.

Нарастил Ярик иглы.

В реке рыбки подросли.

Топчут берег кулички.

Ёрш колючий всплыл в реке.

Он всё ж ещё на высоте,

Его хозяином зовут.

Дань признанья отдают.

Чтоб отведать ёрша власть,

Гору костей надо накласть.

Какая вкусная уха! (щерба)

И под стать его икра.

Кинешь удочку в реку.

Клева ждёшь на берегу.

Глядь, большушие круги.

Дернуть удочку спеши! 

Вместо рыбины большой
Наш хозяин удалой.
Заглотил крючок, но вот,
В наши руки не идёт.

Творчество Вяловой носит преимущественно автобиографический характер и опирается главным образом на местные традиции. Она творчески обрабатывает сказки, которые слышала еще ребенком, в основу многих ее рассказов легли поверья, знакомые ей с детства. Помимо собственных рассказов, она сознательно собирает сказки и предания для своих выступлений: изучает имеющиеся в библиотеке сборники фольклора народов Севера, а также беседует со своими знакомыми, слушает их рассказы.

Действующие лица ее стихов - герои хантыйских преданий, божества, духи, чудовища, простые люди, лесные звери. Эти же персонажи встречаются и на вырезанках, служащих иллюстрациями для текстов: животные, растения, лес, рыбаки и охотники, хантыйские божества. Именно сказки и предания, составляющие основу выступлений Вяловой, обнаруживают наибольшую близость к культуре васюганских ханты, тем не менее в ее отношении к народным поверьям также наблюдается принцип бриколажа [41]. Ее картина мира изменчива, основана на своеобразной идеализированной естественной религии, в которой все взаимосвязано, ничего не происходит случайно, каждая вещь пребывает не только на своем месте, но вещи имеют также магическое содержание [6]. Смелые ассоциации связывают друг с другом явления мира и различных культур. Этот мир населяют такие Лесные и Водяные духи, Лесные женщины и Хозяйки огня, которые могут существовать и в любой другой религии. Так, например, в наборе открыток под названием «Обережка» [42] Вялова соединяет не только элементы, соотносящиеся с религиозными представлениями ханты или с поверьями, широко распространенными в Сибири и в России, но смело вовлекает и такие мотивы, которые имеют весьма отдаленное отношение к народам Сибири: пчела - символ богини Дианы, а птичье перо отсылает к символике египетских богов Ра и Тота.

Вялова не требует от себя филологической точности. Это обнаруживается как в ее бриколаже, так и в возможных ошибках и неточностях: к примеру, в представлении ханты Солнце олицетворяет женское начало, тогда как в ее рассказах Солнце выступает в образе мужчины.

Важным элементом выступлений Вяловой является ее самодельный хантыйский костюм. Она часто объясняет слушателям его строгую символику, так как, по ее словам, каждая деталь что-нибудь означает, одежду не просто так украшали. Пуговицы на платье символизируют птичьи следы; красный платок на голове служит оберегом; красная полоса на рукаве нужна для того, чтобы руки не болели; красная лента на ногах - тоже амулет; а узоры на обуви символизируют воду, небо и землю.

В ее рассказах птицы - не просто животные, но и носители душ, птицы удачи. Лес одновременно дружелюбен и враждебен, так как его постоянным обитателем является медведь, «Хозяин Леса», «Вечно живущий», который представляется и зверем, и человеком, и самой вселенной: «Пойдешь в лес, Он - за елками, вверху, спереди, сзади» [7]. 
Итак, в области сочинительства Вялова - любитель, автодидакт, типичный пример «писателя-труженика» (travailleur) [43-45]. Придя в литературу извне, из неблагоприятных условий, она прилагает огромные усилия, чтобы соответствовать тому культурному, литературному идеалу, который поставила перед собой. Поскольку Вялова представляет местные традиции, а также активно участвует в различных мероприятиях и общественной деятельности, то в местном обществе она занимает важное место и может рассчитывать на широкое признание.

Вместе с тем Вялова - автодидакт не только в области литературы, но и в области науки. Все чаще ее приглашают на научные конференции, где она выступает как с коллекцией своих картин, так и с докладами. В одной из комнат своего дома она устроила музей. Однако, несмотря на то, что время от времени ей приходится писать статьи, она чувствует, что научный текст - на самом деле не ее жанр: «Пишу, а руки тянутся к бумаге и ножницам. Творить, творить!» [16. С. 128]. Темой ее статей и докладов является прежде всего собственное творчество и его роль в школьном образовании, но писала она также и статью по описательной этнографии [6].

Читая научные работы Вяловой, можно отметить, что в них усматривается тот особый тип текста, который Зита Регер и Каталин Ковальчик определяют термином «наивная наука», когда написанные о цыганах самими же цыганами (квази)научные статьи они интерпретируют как своего рода наивное искусство [46]. Точно так же и для творческой стратегии Вяловой характерны, во-первых, свойственные сказкам пространственно-временные рамки, в которых все что угодно может быть связано с чем угодно, и в которых ханты могут быть определены как древняя культура, существующая здесь уже много тысяч лет [5. С. 90]. В этих работах, во-вторых, отсутствуют постановка научной задачи и научный аппарат, таксономия непоследовательна и носит случайный характер, и, несмотря на то, что Вялова пытается следовать формальным требованиям научного текста, она, по сути дела, не аргументирует, а рассказывает истории, не анализирует, а распространяет знания ${ }^{1}$. В свои работы она включает любую научную мысль, которую считает пригодной, и, не обосновывая необходимости ее применения, представляет данную мысль как неопровержимое доказательство своего утверждения ${ }^{2}$. В-третьих, терминология Вяловой также отличается от научной и носит случайный характер. Особенно свободны ее ассоциации в области этимологии: на основе поверхностных, формальных сходств она приходит к неожиданным заключениям ${ }^{3}$. Аргументация Вяловой также весьма упрощенна, вместо научной достоверности она стремится прежде всего к достоверности субъективной. Практически во всех научных работах присутствует ее биография и личный жизненный опыт, подтверждающие легитимность ее утверждений.

Научную деятельность Вялова воспринимает как своего рода приключение, подлинным же средством самовыражения для нее является искусство. Вместе с тем научные работы Вяловой преследуют ту же цель, что и ее творчество: возрождение и сохранение хантыйской культуры. За ее научной дея-

\footnotetext{
${ }^{1}$ Ср. заметки о матриархате у васюганских ханты [9. С. 48].

${ }^{2} \mathrm{Cp}$. использование психологии восприятия цвета в собственной интерпретации цветовой символики [6].

${ }^{3}$ Ср. расшифровку значения фамилии Мурасов как 'человек с Сыни' [9. С. 46].
} 
тельностью необходимо видеть повышение этнополитической активности малых народов Сибири, их стремление к восстановлению своей этнической, национальной культуры.

Таким образом, в сфере науки Вялова - всего лишь любитель, однако ее деятельность невозможно правильно оценить без учета той роли, которую играют в России выходцы из коренных народов, так называемые «коренные антропологи» (native anthropologist) [47]. Балзер [48] обращает внимание на то, что для «коренных антропологов» этнография не просто наука, но и политическая, общественная деятельность, средство борьбы за этническое самосохранение. Они обладают четким сознанием своей миссии, их главной целевой аудиторией является собственная этническая община. Помимо научного интереса к более глубокому изучению родной культуры, они считают принципиальной задачей рассказать и показать эту культуру тем, кто, возможно, уже отдалился от нее, и пробудить в них гордость за «свою» культуру. Кроме этой культурной миссии, они, как правило, ставят перед собой и другие задачи: в Сибири таковыми являются прежде всего борьба с экологическим разрушением и возрождение притесненной в советский период «аутентичной» религиозной жизни [49]. Достижению этнополитических целей, в свою очередь, способствует обращение накопленного в других сферах жизни капитала в политический капитал: так, наличие ученой степени придает больший политический вес, обеспечивает большее пространство для активистской деятельности.

«Коренной исследователь» - так же, как и Вялова - знает свою культуру с рождения, т.е. имеет о ней так сказать «аутентичные» знания, поэтому смело называет себя исследователем культуры: выступает на конференциях, участвует в научных дискуссиях ${ }^{1}$. «Академическое» научное сообщество отчасти (главным образом, в Сибири) признает легитимность такой деятельности, что обусловлено прежде всего отношением данных исследователей к национально-этнической политике. Этим объясняются как многочисленные приглашения на конференции, так и то, что сейчас уже и общественное мнение не ставит под сомнение их научную компетентность. Вялова также все чаще выступает на страницах прессы как исследователь, краевед и этнограф [26], изучающий культуру ханты и селькупов [1].

\section{Заключение}

Рассмотрев подробнее жизнь и творчество Надежды Брониславовны Вяловой, становится понятным, почему глава райадминистрации представил ее как самую известную личность не только района, но и области. Вялова представительница народа ханты, мастер декоративно-прикладного искусства. Она освоила самобытную технику - искусство вырезания картин из бумаги. Вялова экспонирует свои работы на многочисленных выставках, а также занимается просветительской деятельностью: с выступлениями она посещает детские учреждения, чтобы привлечь свою главную аудиторию детей. Техника Вяловой, которая первоначально не была традиционной для васюганских ханты, вызвала интерес аудитории, благодаря чему художнице

1 Здесь можно упомянуть термины Габора Дяни «публичная наука», «публичная культурология», понимаемые исследователем в значении «публичная история», «public history»: Gyáni Gábor. Nemzet, kollektív emlékezet és public history // Történelmi Szemle LIV. 2012. 3. S. 357-375. 
удалось включить эту десятилетиями игнорировавшуюся этническую группу в публичные дискурсы района и области. Самым главным своим достижением она считает то, что ее искусство стало «товарным знаком» васюганских ханты, и, кроме того, приобрело локальный характер, считается брендом Каргасокского района. Творчество Вяловой определенно вписывается в тот контекст, который сформировался сегодня в сибирских регионах: этнические группы, утратившие традиционный образ жизни и народное творчество, в процессе становления этнического самосознания восстанавливают традиционные культурные формы и создают новые - «изобретают» традиции.

Наиболее существенна деятельность Вяловой в области искусства, но активное участие она принимает и в научной жизни. Вялова - художник и исследователь-автодидакт, «труженик» как в сфере искусства, так и в сфере науки. Активность «коренных антропологов» редко обретает четкие рамки, они, как правило, часто переходят от одной сферы деятельности к другой: могут быть политиками, экоактивистами, религизоными, спиритуальными руководителями или же художниками, как Вялова. Вероятно, основное различие между «тружеником» и «коренным антропологом» заключается в том, что первый реже становится политическим деятелем, поскольку для него характерно прежде всего стремление к самоосуществлению, самовыражению, тогда как последний ставит перед собой также (этно)политические, социальные задачи.

\section{Литература}

1. Мастер сибирских вырезанок. URL: http://tomsk-novosti.ru/master-sibirskih-vyrezanok/ (дата обращения: 20.08.2019).

2. Каргасокский район Томской области: официальный сайт. URL: http://www.kargasok.ru/ (дата обращения: 20.08.2019).

3. Золтан H. Васюганские ханты. Изменение религиозной системы в XIX-XXI веках / пер. с венг. Д. Пушкаш. Томск : Изд-во Томского гос. пед. ун-та, 2011. 294 с.

4. Вялова Н.Б. Жизнь в рифме. Стихи. Каргасок : Каргасокская центральная районная библиотека, 2015.

5. Вялова Н.Б. Роль декоративно-прикладного творчества в возрождении и сохранности культуры ханты // Научно-теоретические и методические основания организации профильнопрофессионального обучения в сельской школе : материалы Всерос. науч.-практ. конф. с междунар. участием, г. Томск, 28-29 октября 2010 г. Томск : Изд-во ТГПУ, 2011. С. 90-94.

6. Вялова Н.Б. Из истории национального костюма хантов : Рукопись. б.г., б.м. С. 1.

7. Петриченко А.А. Образ земли хантов // Восточная коллекция. 2010. № 4. С. 130-135.

8. Уникальное искусство. Как хантыйский краевед-этнограф Надежда Вялова из бумаги сказки вырезает $=$ https://obzor.city/article/387998 (дата обращения: 20.08.2019).

9. Вялова Н.Б. Предания таежного края // Проблемы изучения, сохранения и использования искусства вырезки // Материалы международного симпозиума, посвященного 95-летию со дня рождения Алексея Максимовича Петриченко. Домодедово, 2006. С. 46-49.

10. Elliot, Richard - Davies, Andrea. Symbolic brands and authenticity of identity performance. // Jonathan E. Schroeder - Miriam Salzer-Mörling (eds.): Brand Culture. London : Routledge, 2006. P. $155-170$.

11. Вялова Н.Б. Сибирские вырезанки. Томск : D-Print, 2013.

12. Мейко T. Сказки среднего мира. Томск : Красное знамя, 2014.

13. Наследие... = http://www.sokik.ru/vyalova_n_b_v_smi-3003.html (дата обращения: 20.08.2019).

14. Поздравляем и гордимся!!! = http://www.sokik.ru/news-5961.html (дата обращения: 20.08.2019).

15. Nagy Zoltán. The labyrinth of identity: Khanty ethnic identity, its alternatives, and their place in the discourses of identity //Congressus Duodecimus Internationalis Fenno-Ugristarum, Oulu 2015. 
Plenary Papers Mantila, Harri - Leinonen, Kaisa - Brunni, Sisko - Palviainen, Santeri - Sivonen, Jari (ed.) /Studia Humaniora Ouluensia. Oulu : University of Oulu, 2015. P. 87-108.

16. Вялова Н.Б. О земле моей слово // Искусство вырезания из бумаги как способ общения : материалы 3-го Междунар. симп., посвящ. памяти Юлии Даниляускене. Домодедово, 2010. C. $126-128$.

17. Лукина Н.В. Альбом хантыйских орнаментов (восточная группа). Томск : Изд-во Том. ун-та, 1979.

18. Сирелиус Уно Тави. Путешествие к хантам / пер. Н.В. Лукиной. Томск : Изд-во Том. ун-та, 2001.

19. Кулемзин В.М., Лукина Н.В. Легенды и сказки хантов. Томск : Изд-во Том. ун-та, 1973.

20. Хантыйская коллекция ТОКМ : каталог / сост. Н.А. Тучкова. Томск : Изд-во Том. унта, 2001.

21. Могутаев М.К. Хантыйско-русский словарь (васюганский диалект). Томск : Изд-во ТГПУ, 1996. С. 93: «Кавлак - сумка с отделениями для хранения иголок, ниток и другой мелочи».

22. Лукина Н.В., Соколова 3.П., Сязи А.М. Ханты. Декоративное искусство // Народы Западной Сибири. М. : Наука, 2005. С. 193-198.

23. ТГПУ учится у Надежды Вяловой $=$ http://www.sokik.ru/news-4243.html

24. Каргасокская делегация приняла участие в VII международном конкурсе-фестивале «Праздник Топора» = http://www.sokik.ru/news-5297.html (дата обращения: 20.08.2019).

25. Рындина О.М. Я рисую ножницами... // Сибирские вырезанки. Надежда Вялова. Томск : Изд-во D-Print, 2013. С. 3-7.

26. Сибирские вырезанки = http://www.sokik.ru/news-3568.html (дата обращения: 20.08.2019).

27. Бурыкин А.А. Некоторые проблемы социокультурного развития малочисленных народов Севера РФ в свете гендерного подхода // Расы и народы. Вып. 28. М., 2002. С. 188-213. http://static.iea.ras.ru/books/Rasy_i_narody_28.pdf

28. Кочелева Е.Ю. Трансформационные процессы в духовной культуре селькупов и хантов Томской области в 1990-2000-е годы // Вестник Томского государственного педагогического университета. 2007. Вып. 3 (66). С. 168-173. URL: http://vestnik.tspu.edu.ru/files/vestnik/PDF/articles/kosheleva_e. yu._168_173_3_66_2007.pdf

29. Кочелева Е.Ю. Этнические движения коренных малочисленных народов Севера. Западносибирский регион, рубеж 20-21 веков. Saarbruecken : Lambert Academic Publishing. 2012. C. 308 .

30. Игнатенко 3.А. Культура современных селькупов Томской области // Проблемы историко-культурного развития древних и традиционных обществ Западной Сибири и сопредельных территорий. Томск, 2005. С. 249-251.

31. Тучкова Н.А. Художественная самодеятельность и фольклоро-мифо-творческий процесс как этноконсолидирующие факторы, стимулирующие рост этнической идентичности (по материалам Парабельского района Томской области) // Томский журнал лингвистики и антропологии. 2015. № 2 (8). С. 102-111.

32. Ким А.А., Кудряшова Т.К., Кудряшова Д.А. Селькупский праздник в Пиль-эд и культ лося // Материалы и исследования культурно-исторических проблем народов Сибири. Томск, 1996. C. 219-212.

33. Horváth Csilla. Régi problémák, új megoldások: manysi nyelvtanítás az alternatív és közoktatási intézményekben // Nyelvtudományi Közlemények 2014. 67-78.

34. Коробейникова (Малькова) И.А. Проблема обратного перевода фольклорных текстов: с русского языка на селькупский // Самодийцы. Тобольск; Омск, 2001. С. 274-280.

35. Функ Д.А. О современном положении языков малочисленных тюркских народов Южной Сибири (в контексте применимости Европейской хартии региональных языков и языков меньшинств) // Этнографическое обозрение. № 4. 2010. С. 132-140.

36. Hobsbawm, Erik. Tömeges hagyomány-termelés: Európa 1870-1914 // Hagyomány és hagyományalkotás. Budapest, 1987. 127-189. Szerk: Hofer Tamás és Niedermüller Péter.

37. Kovács Ákos. A kitalált hagyomány. Pozsony: Kalligram, 2006.

38. Nagy Zoltán. The forest: religious and narrative symbol of a disintegrating society // Bela Mosia (ed.). Shota Meskhia State Teaching University of Zugdidi. Annual Scientific Work 2015. Book of Scientific Works of the Conference of Belief Narrative Network of ISFNR. Zugdidi : Shota Meskhia State Teaching University, 2015. P. 121-125.

39. Главам районов рассказали как действовать, если все-таки придется затягивать пояса $=$ http://www.sokik.ru/news-6228.html 
40. Живем одной семьей $=$ http://www.sokik.ru/news-7025.html

41. Lévi-Strauss, Claude. The Savage Mind. Chicago, University of Chicago Press, 1966.

42. Вялова Н.Б. Обережка. Набор открыток. Каргасок, Корг Сохи, 2014(a).

43. Lyons Martin: La culture littéraire des travailleurs. Autobiographies ouvriers dans l'Europe de XIXe siecle // Annales. HSS. 2001. 4-5. P. 927-946.

44. Keszeg Vilmos. Csángó írástudók, csángó költészet. б.г. $=$ http://www.keszeg.adatbank.transindex.ro/belso.php? $\mathrm{k}=3 \& \mathrm{p}=2124$

45. Keszeg Vilmos. Alfabetizáció, írásszokások, populáris írásbeliség. Kolozsvár: KJNT - BBTE Magyar Néprajz és Antropológia Tanszék, 2008. P. 249-282.

46. Kovalcsik Katalin, Réger Zita. A tudomány mint naiv müvészet, Kritika, 1995/2, 31-34.

47. Nagy Zoltán. Sámántánc a konferencián: a néprajztudomány teologizálódása Oroszországban. $=$ Ethnographia 125/2014, № 2. P. 234-249.

48. Balzer (Mandelstamm), Marjorie. What's „Native” About Non-Russian Anthropology? // Culture Incarnate: Native Anthropology from Russia. New York : Armont, 1995. P. 3-28.

49. Харитонова В.И. Феникс из пепла? Сибирский шаманизм на рубеже тысячелетий. М. : Ин-т этнологии и антропологии им. Н.Н. Миклухо-Маклая РАН, 2006.

Nagy Zoltán, University of Pécs (Pécs, Hungary).

E-mail: nagyzooli@gmail.com

Vestnik Tomskogo gosudarstvennogo universiteta. Kul'turologiya i iskusstvovedeniye - Tomsk State University Journal of Cultural Studies and Art History, 2019, 35, p. 222-241.

DOI: $10.17223 / 22220836 / 35 / 21$

THE KEEPER WHO PUT THE KHANTY OF THE VASYUGAN ON THE MAP

Keywords: Khanty; Western-Siberia; invented tradition; heritage language; indigenous anthropologist; folklorisation.

My paper deals with a problem, how people can use and revitalize the, so called traditional culture of the indigenous ethnic minorities in a situation, when the continuity of a culture was broken, and the activists have not got any possibility to use a kind of organic tradition. Furthermore I deal with a problem, how to appreciate, how to accept the public opinion of this (re)invented tradition.

In this paper I present this question by demonstrating the curriculum vitae and an artist's oeuvre. The geographic field of my research is Western-Siberia and the Khanty people, especially N.B. Vyalova an artist who considers herself as a Khanty, in the district of Kargasok, Tomsk county, where $90 \%$ of the population is Russian and the Khanty do not amount to $1 \%$.

In this paper I delineate Vyalova's biography, and analyse how did she discovered her form of self-expression: paper-cutting, and how she based this forms of art on her curriculum vitae. Furthermore I show the way how she became more and more versatile and complex artist, and how she create the aura of authenticity with the help of - for example - using the khanty language, which she never learnt to speak. After the analysis of the question of authenticity, I interpret her work as a naive, autodidactic art, and her permanently evolving academic life's-work as autodidactic, popular science, since her activity is prominent not only in art but she is present in science, too. The activity of ,native anthropologists" rarely articulates itself in a straightforward way. They often oscillate back and forth between different fields: they may become politicians, ecological activists, religious-spiritual leaders or, as is the case of Vyalova, artists. Building Khanty art into a successful brand, she has smuggled back the Khanty into public discourse after several decades of exclusion.

Based on long term participating fieldwork and on written sources such as local press products, publications on the interfaces of social media and also the artistic and scientific works of Vyalova herself, I interpret her oeuvre in a social-cultural anthropological perspective using technical terms like ,invented tradition”, „native anthropologist”, „folklorization” and „heritage language”.

Summarised: I examine specifically how her art fits into present-day Siberian socio-cultural context in which social groups that had lost their traditional ways of life and art but experience a phase of ethnic revival, revive traditional cultural forms that can be learnt back or else, create new ones: they invent new traditions.

\section{References}

1. Sukhoveiko, T. (2015) Master sibirskikh vyrezanok [Master of Siberian carving]. [Online] Available from: http://tomsk-novosti.ru/master-sibirskih-vyrezanok/ (Accessed: 20th August 2019).

2. Kargasok District, Tomsk Region. (n.d.) Official Website. [Online] Available from: http://www.kargasok.ru/ (Accessed: 20th August 2019). 
3. Nagy, Z. (2011) Vasyuganskie khanty. Izmenenie religioznoy sistemy v XIX-XXI vekakh [Vasyugan Khanty. Changes in the religious system in the 19th -21 st centuries]. Translated from Hungarian by D. Pushkash. Tomsk: Tomsk State Pedagogical University.

4. Vyalova, N.B. (2015) Zhizn'v rifme. Stikhi [Life is in Rhyme. Poems]. Kargasok: Kargasok Central District Library.

5. Vyalova, N.B. (2011) [The role of arts and crafts in the revival and preservation of the culture of the Khanty]. Nauchno-teoreticheskie $i$ metodicheskie osnovaniya organizatsii profil'noprofessional'nogo obucheniya $v$ sel'skoy shkole [Scientific, Theoretical and Methodological foundations for the Organization of Vocational Ttraining in a Rural School]. Proc. of the All-Russian Conference. Tomsk. October 28-29, 2010. Tomsk: Tomsk State Predagogical University. pp. 90-94. (In Russian).

6. Vyalova, N.B. (n.d.) Iz istorii natsional'nogo kostyuma khantov [From the history of the Khanty national costume]. [Manuscript]. [s.l.; s.n.].

7. Petrichenko, A.A. (2010) Obraz zemli khantov [The image of the Khanty land]. Vostochnaya Kollektsiya. 4. pp. 130-135.

8. Simonova, M. (2013) Unikal'noe iskusstvo. Kak khantyyskiy kraeved-etnograf Nadezhda Vyalova iz bumagi skazki vyrezaet [The unique art. How the Khanty ethnographer Nadezhda Vyalova cuts out paper fairy-tales]. [Online] Available from: https://obzor.city/article/387998 (Accessed: 20th August 2019).

9. Vyalova, N.B. (2006) Predaniya tayezhnogo kraya [Legends of the taiga]. In: Polunina, N.M. (ed.) Problemy izucheniya, sokhraneniya i ispol'zovaniya iskusstva vyrezki [Problems of Studying, Preserving and Using the Art of Carving]. Proc. of the International Symposium. Domodedovo. pp. 46-49.

10. Elliot, R. \& Davies, A. (2006) Symbolic brands and authenticity of identity performance. In: Schroeder. J.E. \& Salzer-Mörling, M. (eds) Brand Culture. London: Routledge. pp. 155-170.

11. Vyalova, N.B. (2013) Sibirskie vyrezanki [Siberian papercuts]. Tomsk: D-Print.

12. Meyko, T. (2014) Skazki srednego mira [Tales of the Middle World]. Tomsk: Krasnoe Znamya.

13. Severnaya Pravda. (n.d.) Nasledie...[Heritage . . .]. [Online] Available from: http://www.sokik.ru/vyalova_n_b_v_smi-3003.html (Accessed: 20th August 2019).

14. Sokik.ru. (n.d.) Pozdravlyaem i gordimsya!!! [Congratulations!!! We are proud!]. [Online] Available from: http://www.sokik.ru/news-5961.html (Accessed: 20th August 2019).

15. Nagy, Z. (2015) The labyrinth of identity: Khanty ethnic identity, its alternatives, and their place in the discourses of identity. In: Mantila, H., Leinonen, K., Brunni, S., Palviainen, S. \& Sivonen, J. (eds) Congressus Duodecimus Internationalis Fenno-Ugristarum, Oulu 2015. Oulu: University of Oulu. pp. 87-108.

16. Vyalova, N.B. (2010) O zemle moey slovo [A word about my land]. Iskusstvo vyrezaniya iz bumagi kak sposob obshcheniya [The Papercutting Art as a Way of Communication]. Proc. of the 3rd International Symposium. Domodedovo. pp. 126-128. (In Russian).

17. Lukina, N.V. (1979) Al'bom khantyyskikh ornamentov (vostochnaya gruppa) [The Album of Khanty Ornaments (the Oriental group)]. Tomsk: Tomsk State University.

18. Sirelius, U.T. (2001) Puteshestvie $k$ khantam [Travel to the Khanty]. Translated by N.V. Lukina. Tomsk: Tomsk State University.

19. Kulemzin, V.M. \& Lukina, N.V. (1973) Legendy i skazki khantov [The Khanty Legends and Tales]. Tomsk: Tomsk State University.

20. Tuchkova, N.A. (2001) Khantyyskaya kollektsiya TOKM [The Khanty collection of the Tomsk Museum of Local Lore Studes]. Tomsk: Tomsk State University.

21. Mogutaev, M.K. (1996) Khantyysko-russkiy slovar' (vasyuganskiy dialekt) [The KhantyRussian dictionary (Vasyugan dialect)]. Tomsk: Tomsk State Pedagogical University. pp. 93.

22. Lukina, N.V., Sokolova, Z.P. \& Syazi, A.M. (2005) Dekorativnoe iskusstvo [Decorative art]. In: Gemuev, I.N. (ed.) Narody Zapadnoy Sibiri [Peoples of Western Siberia]. Moscow: Nauka. pp. 193-198.

23. Sokik.ru (2014) TGPU uchitsya u Nadezhdy Vyalovoy [TSPU learns from Nadezhda Vyalova]. [Online] Available from: http://www.sokik.ru/news-4243.html

24. The Kargasok District Administration. (2014) Kargasokskaya delegatsiya prinyala uchastie $v$ VII mezhdunarodnom konkurse-festivale "Prazdnik Topora" [The Kargasok delegation took part in the Seventh International Festival "Axe Holiday"]. [Online] Available from: http://www.sokik.ru/news5297.html (Accessed: 20th August 2019).

25. Ryndina, O.M. (2013) Ya risuyu nozhnitsami... [I draw with scissors ...]. In: Vyalova, N. Sibirskie vyrezanki [Siberian papercuts]. Tomsk: D-Print. pp. 3-7. 
26. Sokik.ru. (n.d.) Sibirskie vyrezanki [Siberian papercuts]. [Online] Available from: http://www.sokik.ru/news-3568.html (Accessed: 20th August 2019).

27. Burykin, A.A. (2002) Nekotorye problemy sotsiokul'turnogo razvitiya malochislennykh narodov Severa RF v svete gendernogo podkhoda [Some problems of the socio-cultural development of the small peoples of the North of the Russian Federation in the light of the gender approach]. In: Sokolva, Z.P. \& Funk. D.A. (eds) Rasy i narody [Races and Peoples]. Vol. 28. Moscow: Nauka. pp. $188-213$.

28. Kosheleva, E.Yu. (2007) Transformations of Mental Culture of Selkups and Khanty Living in Tomsk Oblast (1990s - 2000s). Vestnik Tomskogo gosudarstvennogo pedagogiche-skogo universiteta - Tomsk State Pedagogical University Bulletin. 3(66). pp. 168-173. (In Russian). [Online] Available http://vestnik.tspu.edu.ru/files/vestnik/PDF/articles/kosheleva_e._yu._168_173_3_66_2007.pdf from:

29. Kosheleva, E.Yu. (2012) Etnicheskie dvizheniya korennykh malochislennykh narodov Severa. Zapadnosibirskiy region, rubezh 20-21 vekov [Ethnic movements of indigenous peoples of the North. West Siberian region, the boundary of the 20-21 centuries]. Saarbruecken: Lambert Academic Publishing.

30. Ignatenko, Z.A. (2005) Kul'tura sovremennykh sel'kupov Tomskoy oblasti [The culture of modern Selkups of Tomsk Region]. In: Chindina, L.A. (ed.) Problemy istoriko-kul'turnogo razvitiya drevnikh i traditsionnykh obshchestv Zapadnoy Sibiri i sopredel'nykh territoriy [Problems of historical and cultural development of ancient and traditional societies of Western Siberia and adjacent territories]. Tomsk: Tomsk State University. pp. 249-251.

31. Tuchkova, N.A. (2015) Folk performing arts and folk myth creation process as ethnic consolidation factors stimulating ethnic identity development (based on data from Parabel district of Tomsk Region). Tomskiy zhurnal lingvistiki i antropologii - Tomsk Journal of Linguistics and Anthropology. 2(8). pp. 102-111. (In Russian).

32. Kim, A.A., Kudryashova, T.K. \& Kudryashova, D.A. (1996) Sel'kupskiy prazdnik v Pil'-ed i kul't losya [Selkup holiday in Pil-ed and the cult of the moose]. In: Chindina, L.A. (ed.) Materialy $i$ issledovaniya kul'turno-istoricheskikh problem narodov Sibiri [Materials and Studies of Cultural and Historical Problems of Siberian Peoples]. Tomsk: Tomsk State University. pp. 219-212.

33. Horváth, C. (2014) Régi problémák, új megoldások: manysi nyelvtanítás az alternatív és közoktatási intézményekben. Nyelvtudományi Közlemények. pp. 67-78.

34. Korobeynikova (Malkova), I.A. (2001) Problema obratnogo perevoda fol'klornykh tekstov: s russkogo yazyka na sel'kupskiy [The problem of the reverse translation of folklore texts: from Russian to Selkup]. In: Samodiytsy [Samodians]. Tobolsk; Omsk: [s.n.]. pp. 274-280.

35. Funk, D.A. (2010) O sovremennom polozhenii yazykov malochislennykh tyurkskikh narodov Yuzhnoy Sibiri (v kontekste primenimosti Evropeyskoy khartii regional'nykh yazykov i yazykov men'shinstv) [On the current situation of the languages of small Turkic peoples in South Siberia (in the context of the European Charter for Regional and Minority Languages)]. Etnograficheskoe obozrenie Ethnographic Review. 4. pp. 132-140.

36. Hobsbawm, E. (1987) Tömeges hagyomány-termelés: Európa 1870-1914. In: Hofer, T. \& Niedermüller, P. (eds) Hagyomány és hagyományalkotás. MTA Néprajzi Kutató Csoportja. pp. 127-189.

37. Kovács, Á. (2006) A kitalált hagyomány. Pozsony: Kalligram.

38. Nagy, Z. (2015) The forest: religious and narrative symbol of a disintegrating society. In: Bela Mosia. (ed.) Shota Meskhia State Teaching University of Zugdidi. Annual Scientific Work 2015. Book of Scientific Works of the Conference of Belief Narrative Network of ISFNR. Zugdidi: Shota Meskhia State Teaching University. pp. 121-125.

39. Sokik.ru. (2015) Glavam rayonov rasskazali kak deystvovat', esli vse-taki pridetsya zatyagivat' poyasa [The heads of districts were told how to act if they still have to tighten their belts]. [Online] Available from: http://www.sokik.ru/news-6228.html

40. Sokik.ru. (2016) Zhivem odnoy sem'ey [We live as one family]. [Online] Available from: http://www.sokik.ru/news-7025.html

41. Lévi-Strauss, C. (1966) The Savage Mind. Chicago, IL: University of Chicago Press.

42. Vyalova, N.B. (2014) Oberezhka. Nabor otkrytok [Charm. A set of greeting cards]. Kargasok: Korg Sokhi.

43. Lyons, M. (2001) La culture littéraire des travailleurs. Autobiographies ouvriers dans l'Europe de XIXe siècle. Annales. HSS. 4-5. pp. 927-946.

44. Keszeg, V. (n.d.) Csángó írástudók, csángó költészet. [Online] Available from: http://www.keszeg.adatbank.transindex.ro/belso.php?k=3\&p=2124 
45. Keszeg, V. (2008) Alfabetizáció, irásszokások, populáris irásbeliség. Kolozsvár: KJNT BBTE Magyar Néprajz és Antropológia Tanszék. pp. 249-282.

46. Kovalcsik, K. \& Réger, Z. (1995) A tudomány mint naiv müvészet. Kritika. 2. pp. 31-34.

47. Nagy, Z. (2014) Sámántánc a konferencián: a néprajztudomány teologizálódása Oroszországban. Ethnographia. 125(2). pp. 234-249.

48. Balzer (Mandelstamm), M. (1995) Culture Incarnate: Native Anthropology from Russia. New York: Armont. pp. 3-28.

49. Kharitonova, V.I. (2006) Feniks iz pepla? Sibirskiy shamanizm na rubezhe tysyacheletiy [Phoenix from the ashes? Siberian shamanism at the turn of the millennium]. Moscow: Institute of Ethnology and Anthropology. 